\title{
Aporte de los inmigrantes a la tuberculosis en un Servicio de Salud de Chile
}

\author{
CARLOS PEÑA M.*, RUTH CAAMAÑO M.*, MARÍA JOSÉ MESA M.**, ROGELIO URZÚA S.**, \\ MATÍAS PINOCHET R.** y CATALINA MIRANDA M.***
}

\section{Contribution of immigrants to tuberculosis in a Health Service in Chile}

The assessment of Chilean Tuberculosis Control Program shows a growing increase of tuberculosis cases in foreign patients in communes of the city of Santiago with higher incidence of this disease. Through the evaluation of the cases diagnosed in a decade we found an increasing contribution of foreigners, ranging from about $10 \%$ in 2005 to $30 \%$ in 2014. The greatest proportion of tuberculosis cases in foreigners was detected in Santiago, the commune with the highest incidence. In this area, tuberculosis incidence ranged from $17 \%$ in 2005 , to $29 \%$ in 2015. Treatment efficiency in foreigners $(87.6 \%)$ is close to our national goal (90\%) and better than in Chilean patients $(81.5 \%)$. We found a higher proportion of foreign cases defaulting therapy (11\%) in relation to Chilean (7.7\%), but the death rate in foreigners was less than in Chileans (1.5 versus 10.6\%). We must strengthen tuberculosis control strategies focused on foreigner populations.

Key words: Tuberculosis in immigrants, Chilean tuberculosis control program.

\section{Resumen}

La evaluación del Programa de Control de la Tuberculosis de Chile muestra un creciente aumento de casos de tuberculosis en pacientes extranjeros en las comunas de Santiago de mayor incidencia de esta enfermedad. Mediante la evaluación de los casos diagnosticados durante una década se comprobó un creciente aporte de casos de tuberculosis en el grupo de inmigrantes, desde cerca de $10 \%$ el año 2005 hasta cerca de 30\% en 2014. La mayor proporción de casos de extranjeros ocurre en la comuna de mayor incidencia (Santiago), con cifras iniciales de 17\% el año 2005, llegando a 29\% en 2015. La eficacia del tratamiento en los inmigrantes $(87,6 \%)$ está cerca de la meta nacional (90\%) y es mejor que la de los chilenos (81,5\%). Encontramos una proporción mayor de casos extranjeros que abandonan la terapia (11\%) en relación a los chilenos $(7,7 \%)$, pero la letalidad en extranjeros es menor $(1,5 \%)$ que la de los chilenos (10,6\%). Se deberán reforzar las estrategias de control de tuberculosis, focalizadas en la población extranjera.

Palabras clave: Tuberculosis en inmigrantes, Programa de control de la tuberculosis en Chile.

\section{Introducción}

La Tuberculosis (TBC) es una enfermedad transmisible que en 1993 fue declarada por la Organización Mundial de la Salud (OMS) una "Emergencia Global" 1 por su alta incidencia (9.000.000 de casos en 2013) y por su elevada mortalidad (actualmente primera causa de muerte por enfermedad infecciosa en el mundo, antes que la debida al virus de la inmunodeficiencia humana). Se trasmite a través de la tos de casos pulmonares que eliminan bacilos en las secreciones respiratorias, la presencia de los cuales se determina mediante el diagnóstico bacteriológico,

\footnotetext{
* Programa de Control de la Tuberculosis. Servicio de Salud Metropolitano Central.

** Estudiantes de Medicina, Universidad de Chile.

***Estudiante de la Carrera de Enfermería, Universidad Diego Portales.
} 
baciloscopia y cultivo del bacilo de Koch, o por la identificación del genoma del bacilo tuberculoso en la expectoración (PCR).

Para hacer frente a esta epidemia la OMS a través de la estrategia "Alto a la Tuberculosis" propone disminuir la carga de TBC hasta eliminarla como problema de salud pública a nivel mundial para el año $2050^{2}$. Las estrategias para el período 2015-2030 consideran reducir las muertes por TBC en $90 \%$ y la incidencia de nuevos casos en $80 \%$, junto con evitar gastos catastróficos para las familias por esta enfermedad $^{3}$. Sin embargo, la globalización, con migración de personas desde regiones de alta endemia hacia otras de menor incidencia de TBC; la mayor esperanza de vida, que aumenta los reservorios de infectados con riesgo de reactivación; la presencia de una creciente población con infección por VIH donde la enfermedad es más prevalente, y el gran aumento de poblaciones urbanas que facilitan la propagación de esta enfermedad, pueden contribuir a la expansión de la TBC, retardando la reducción de su incidencia. El factor que más podría influir en la persistencia de la enfermedad en la población sería la falta de eficiencia de los mecanismos sanitarios de control.

La baja cobertura y reducido impacto de las actividades de control reflejadas en la decreciente pesquisa de los casos de tuberculosis pulmonar bacilífera mediante la baciloscopia de expectoración en sintomáticos respiratorios, unido a la falta de eficacia en lograr tasas satisfactorias de curación de los casos diagnosticados, son quizás los factores que más inciden en el retardo del control epidemiológico de la TBC. El grado de control sanitario a su vez se relaciona con la intensidad y respaldo de las políticas de salud asociadas al desarrollo de las estrategias programáticas que han sido bien definidas por la OMS y por las autoridades de salud de los diferentes países ${ }^{4,5}$.

En Chile las actividades de control han sido organizadas y ejecutadas a nivel nacional desde hace más de 4 décadas, logrando un importante impacto de reducción de la incidencia de la enfermedad. Sin embargo, la declinación anual de las tasas de TBC es menor a partir del año 2000, alcanzando cifras estacionarias a partir del año $2009^{6}$. Los factores de riesgo asociados a TBC en Chile señalan que en 2014, 20\% de los casos son adultos mayores, $8,7 \%$ son coinfectados VIH y $8,4 \%$ son extranjeros ${ }^{7}$. En los últimos tiempos Chile ha recibido una importante cantidad de inmigrantes; más de la mitad de ellos provenientes de Perú, Argentina, Bolivia y
Ecuador, que son países con mayor prevalencia de TBC que la de Chile. Los inmigrantes son un grupo vulnerable para adquirir la TBC, un exceso de 10 a $15 \%$ de casos aportados por ellos podría ser abordable por el programa de tuberculosis, pero existe otro riesgo, el de la multidrogoresistencia ${ }^{8}$.

La Región Metropolitana de Chile registra zonas de alta incidencia de $\mathrm{TBC}$ en las comunas de Santiago, Estación Central, Independencia, Recoleta y San Joaquín. Las dos primeras comunas pertenecen al Servicio de Salud Metropolitano Central (SSMC) que abarca una población de 1.134.084 habitantes y tiene una incidencia de TBC de 14,7 por 100.000 habitantes el año 2014 , siendo el $29 \%$ de sus casos inmigrantes. Las comunas de mayor incidencia fueron Estación Central (38,8 x 100.000) y Santiago (16 x 100.000). Destacamos que ambas comunas son las que registran las mayores tasas de TBC del servicio (promedio entre el año 2007 y 2011 de 52 x 100.000 para Santiago y 44,8 x 100.000 para Estación Central); sin embargo, la comuna de Santiago recientemente ha ido reduciendo progresivamente sus tasas. Estas dos comunas concentran el 66\% de los casos del Servicio de Salud y el $87 \%$ de los casos de TBC en extranjeros.

En la comuna de Santiago, 52\% de casos de TBC pulmonar bacilífera y en Estación Central $23,5 \%$, son inmigrantes 9 . Debido a la alta proporción de $\mathrm{TBC}$ en extranjeros, en las comunas de mayor incidencia, consideramos necesario realizar una investigación para conocer el aporte de los extranjeros a la TBC y conocer sus características con el fin de apoyar la estrategia de pesquisa focalizada en los inmigrantes de estas comunas. Debemos tener presente que detectar estas fuentes de transmisión y tratar la $\mathrm{TBC}$ en forma eficiente y oportuna contribuirá a interrumpir la transmisión de la enfermedad en la comunidad.

\section{Objetivos}

El objetivo principal de este estudio fue cuantificar a los pacientes inmigrantes dentro de la casuística de TBC del SSMC durante una década. Como objetivos secundarios nos planteamos los siguientes: i) conocer la proporción de casos de $\mathrm{TBC}$ en extranjeros que representan fuentes de transmisión (tuberculosis pulmonar bacteriológicamente demostrada); ii) Caracterizar a los pacientes extranjeros con tuberculosis, y iii) conocer la eficacia y eficiencia de la terapia de la tuberculosis en extranjeros. 


\section{Metodología}

Este es un estudio de carácter descriptivo y retrospectivo, en el cual se revisaron los registros de los pacientes del Programa de Control de la Tuberculosis del SSMC con domicilio en las comunas del servicio de salud SSMC. Estos registros se mantienen en el Hospital Clínico San Borja Arriarán. Se incluyeron los casos ocurridos entre el 1 de enero del año 2005 y el 31 de diciembre de 2014. Se revisaron los pacientes diagnosticados que iniciaron tratamiento y se consignaron los siguientes antecedentes: género, edad, dirección de residencia, país de procedencia, antecedente de terapia de TBC, tipo de TBC, año del diagnóstico, grupos de riesgo (VIH, inmigrantes, adulto mayor, consumo de alcohol y drogas, privados de libertad, pueblos originarios, diabetes y otras inmunodeficiencias). Además, tipo de terapia antituberculosa y resultados del tratamiento según criterios de la OMS (éxito terapéutico si el paciente culmina su terapia; abandono o pérdida de seguimiento si registra inasistencia continua a la terapia por más de 30 días; fallecido o muerte si esto ocurre durante el tratamiento, independiente de la causa que la motiva; traslado sin confirmación si es derivado a otro servicio de salud o país, desconociéndose la recepción del caso y los resultados de la terapia en el sitio destinado, y fracaso cuando la baciloscopia es persistentemente positiva hasta el $4^{\circ}$ mes de tratamiento o si luego de hacerse negativa reaparece positiva durante la terapia (debe confirmarse el fracaso con cultivo positivo). Con esta información, autorizada por los encargados del Programa de Control de la TBC del respectivo Servicio de Salud, se construyó una base de datos anónima para mantener la confidencialidad de algunos datos sensibles asociados al diagnóstico (patologías asociadas, hábitos y otros). Los registros se trabajaron en una planilla Excel para cálculos de promedio y proporciones.

\section{Resultados}

\section{Casuística general}

En el Programa de Control de la Tuberculosis del SSMC, durante el período de 10 años se notificaron 2.078 casos de TBC, excluyendo los pacientes con residencia en otras comunas del país $(11,8 \%)$, los casos sin identificación de la nacionalidad y los portadores de micobacterias no tuberculosas, quedando una muestra útil de 1.833 pacientes. Varones fueron 1.275 casos $(69,6 \%)$. El promedio de edad alcanzó a 40 años; 1.341 eran pulmonares $(\mathrm{P})$ lo que representa $73,2 \%$ del total; 1.167 eran TBC pulmonares bacteriológicamente demostrada (PB) y 492 extra-pulmonares (EP). Se conoció el antecedente de VIH en 86 casos $(5 \%)$ y 209 correspondieron a población privada de libertad (11,4\%) (Tabla 1).

\section{Distribución comunal}

La comuna de Santiago registró 859 casos (46,9\%), Maipú 439 (23,9\%) y Estación Central $402(21,9 \%)$ (Tabla 2 y Figura 1). Los casos de TBC pulmonar bacteriológicamente demostrada (PB) fueron 1.167 y se concentraron en la comuna de Santiago, 543 casos $(46,5 \%)$ seguidos de Maipú, 274 casos (29,3\%) y Estación Central, 264 casos $(28,2 \%)$ (Tabla 3 y Figura 2$)$.

\section{Pacientes chilenos y extranjeros}

Se identificaron 380 casos de TBC correspondientes a inmigrantes $(20,7 \%$ del total $)$, de los cuales 224 eran varones. Los pacientes chilenos fueron 1.453 (79,3\% de los casos), de los cuales 1.051 eran varones. El promedio de edad de los pacientes extranjeros fue de 30,2 años, significativamente menor que el promedio de edad del grupo de pacientes chilenos (42,5 años) (Tablas 4 y 5 ).

Entre los inmigrantes hubo 231 casos de TBC pulmonar bacilífera (61\% de los casos de TBC en inmigrantes), proporción que es algo menor que en los chilenos $(64,4 \%)$. Los casos extra-pulmo-

Tabla 1. Características de pacientes con tuberculosis. Programa de Control de la TBC, SSMC 2005 a 2014

\begin{tabular}{|c|c|c|c|c|c|c|c|c|c|c|c|c|}
\hline \multirow{2}{*}{$\begin{array}{c}\text { Casos TBC } \\
\text { Período } \\
\text { 2005-2014 }\end{array}$} & \multicolumn{2}{|c|}{ Género } & \multicolumn{3}{|c|}{$\begin{array}{c}\text { Edad } \\
\text { Promedio (años) }\end{array}$} & \multicolumn{3}{|c|}{ Localización TBC } & \multicolumn{4}{|c|}{ Condición asociada } \\
\hline & $\mathbf{M}$ & $\mathbf{F}$ & Total & M & $\mathbf{F}$ & $\mathbf{P}$ & PB & $\mathbf{E P}$ & VIH & $\begin{array}{l}\text { Privado } \\
\text { libertad }\end{array}$ & Drogas & Alcohol \\
\hline 1.833 & 1.275 & 558 & 40 & 38,7 & 43 & 1.341 & 1.167 & 492 & 86 & 209 & 8 & 9 \\
\hline
\end{tabular}

Las cifras de la tabla representan el número de pacientes. $\mathrm{M}=$ masculino; $\mathrm{F}=$ femenino; $\mathrm{P}=$ pulmonar; $\mathrm{PB}=$ pulmonar bacteriológicamente demostrada; $\mathrm{EP}=$ extra-pulmonar. 
Tabla 2. Casos de tuberculosis según comunas. Programa de Control de la TBC, SSMC 2005 a 2014

\begin{tabular}{|cccccc|}
\hline $\begin{array}{c}\text { Total } \\
\text { de casos }\end{array}$ & Santiago & Maipú & \multicolumn{3}{c|}{$\begin{array}{c}\text { Estación Cerrillos } \\
\text { Central }\end{array}$} \\
\hline 1.833 & 659 & 439 & 402 & 96 & 38 \\
\hline
\end{tabular}

Las cifras de la tabla representan el número de pacientes. $\mathrm{PAC}=$ comuna Pedro Aguirre Cerda.

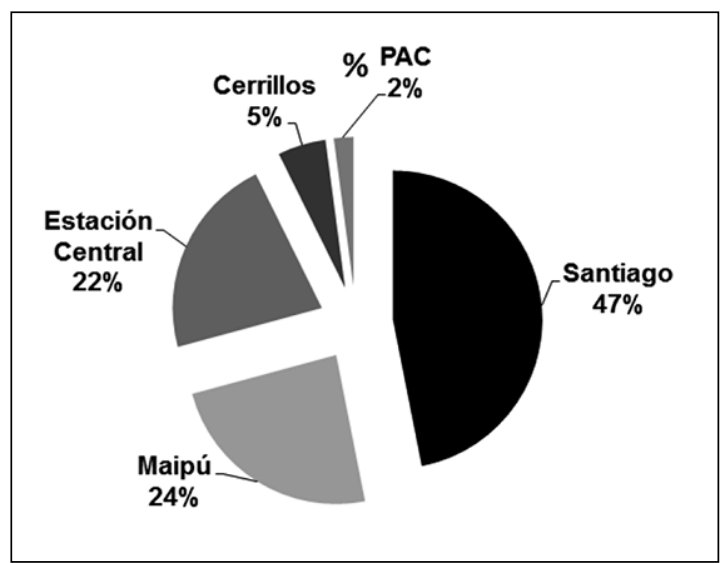

Figura 1. Distribución comunal de la Tuberculosis. Programa de Control de la TBC, SSMC 2005 a 2014. $\mathrm{PAC}=$ comuna Pedro Aguirre Cerda.
Tabla 3. Casos de tuberculosis demostrada bacteriológicamente según comunas. Programa de Control de la TBC, SSMC 2005 a 2014

\begin{tabular}{|ccccccc|}
\hline $\begin{array}{c}\text { Total } \\
\text { de casos }\end{array}$ & Santiago & Maipú & \multicolumn{3}{c|}{$\begin{array}{c}\text { Estación Cerrillos } \\
\text { Central }\end{array}$} \\
\hline 1.167 & 543 & 274 & 264 & 57 & 29 \\
\hline
\end{tabular}

Las cifras de la tabla representan el número de pacientes. $\mathrm{PAC}=$ comuna Pedro Aguirre Cerda.

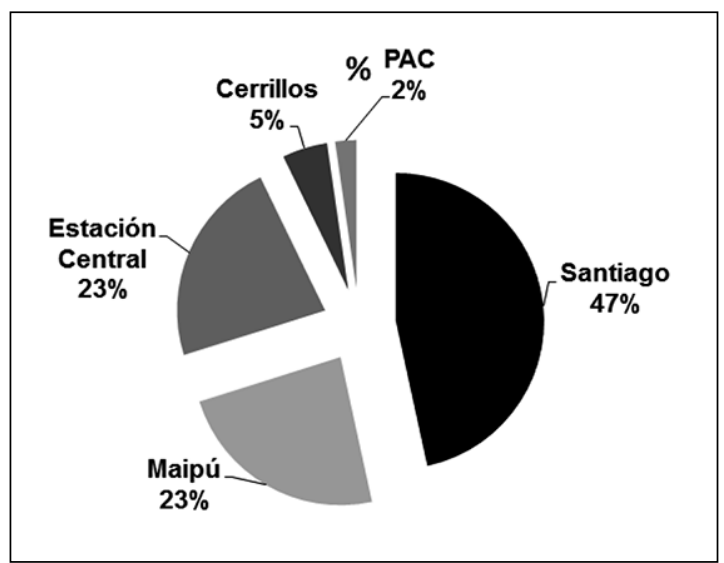

Figura 2. Distribución comunal de tuberculosis bacteriológicamente demostrada. Programa de Control de la TBC, SSMC 2005 a 2014. PAC = comuna Pedro Aguirre Cerda.

Tabla 4. Características de chilenos con tuberculosis. Programa de Control de la TBC, SSMC 2005 a 2014

\begin{tabular}{|c|c|c|c|c|c|c|c|c|c|c|}
\hline \multirow{2}{*}{$\begin{array}{c}\text { Casos TBC } \\
\text { Período } \\
\text { 2005-2014 }\end{array}$} & \multicolumn{2}{|c|}{ Género } & \multirow{2}{*}{$\begin{array}{c}\text { Edad } \\
\text { Promedio } \\
\text { (años) }\end{array}$} & \multicolumn{3}{|c|}{ Localización TBC } & \multicolumn{4}{|c|}{ Condición asociada } \\
\hline & $\mathbf{M}$ & $\mathbf{F}$ & & $\mathbf{P}$ & PB & EP & VIH & $\begin{array}{l}\text { Privado } \\
\text { libertad }\end{array}$ & Drogas & Alcohol \\
\hline 1.433 & 1.031 & 402 & 42,5 & 1.060 & 939 & 393 & 72 & 201 & 8 & 9 \\
\hline
\end{tabular}

Las cifras de la tabla representan el número de pacientes. $\mathrm{M}=$ masculino; $\mathrm{F}=$ femenino; $\mathrm{P}=$ pulmonar; $\mathrm{PB}=$ pulmonar bacteriológicamente demostrada; $\mathrm{EP}=$ extra-pulmonar.

Tabla 5. Características de extranjeros con tuberculosis. Programa de Control de la TBC, SSMC 2005 a 2014

\begin{tabular}{|c|c|c|c|c|c|c|c|c|c|c|}
\hline \multirow{2}{*}{$\begin{array}{c}\text { Casos TBC } \\
\text { Período } \\
\text { 2005-2014 }\end{array}$} & \multicolumn{2}{|c|}{ Género } & \multirow{2}{*}{$\begin{array}{c}\text { Edad } \\
\text { Promedio } \\
\text { (años) }\end{array}$} & \multicolumn{3}{|c|}{ Localización TBC } & \multicolumn{4}{|c|}{ Condición asociada } \\
\hline & $\mathbf{M}$ & F & & $\mathbf{P}$ & PB & EP & VIH & $\begin{array}{l}\text { Privado } \\
\text { libertad }\end{array}$ & Drogas & Alcohol \\
\hline 380 & 224 & 156 & 30,2 & 281 & 231 & 99 & 14 & 8 & 0 & 0 \\
\hline
\end{tabular}

Las cifras de la tabla representan el número de pacientes. $\mathrm{M}=$ masculino; $\mathrm{F}=$ femenino; $\mathrm{P}=$ pulmonar; $\mathrm{PB}=$ pulmonar bacteriológicamente demostrada; $\mathrm{EP}=$ extra-pulmonar.

Tabla 6. Distribución de formas de TBC Extra-pulmonar. Programa de Control de la TBC, SSMC 2005 a 2014

\begin{tabular}{|lcccccc|}
\hline Localización de TBC & \multicolumn{2}{c}{ Extranjeros } & \multicolumn{2}{c}{ Chilenos } & \multicolumn{2}{c|}{ Total } \\
Extrapulmonar & $\mathbf{n}$ & $\mathbf{\%}$ & $\mathbf{n}$ & $\mathbf{\%}$ & $\mathbf{n}$ & $\mathbf{\%}$ \\
\hline Ganglionar & 33 & 33,3 & 116 & 29,5 & 149 & 30,3 \\
\hline Pleural & 32 & 32,3 & 113 & 28,8 & 145 & 29,5 \\
Otras localizaciones & 34 & 34,4 & 164 & 41,7 & 198 & 40,2 \\
\hline Total & 99 & & 393 & & 492 & \\
\hline
\end{tabular}


nares (EP) fueron 492. Las formas más frecuentes fueron TBC ganglionar, 149 casos $(30,3 \%)$ y pleural con 145 casos $(29,5 \%)$. La proporción de EP es similar en extranjeros $(26 \%)$ y chilenos (27\%). Las localizaciones EP más frecuentes también son similares en inmigrantes y chilenos: las formas ganglionares alcanzan a $33,3 \%$ en inmigrantes y a $29,5 \%$ en chilenos, y las pleurales representan el 32,3\% de las localizaciones EP en inmigrantes y $28,8 \%$ en chilenos (Tabla 6 ).

La comuna de Santiago concentra el $69,2 \%$ (263 casos) de casos originados en inmigrantes y captura al $41 \%$ de los casos chilenos (596 casos).

Tabla 7. Extranjeros con TBC según comunas. Programa de Control de la TBC, SSMC 2005 a 2014

\begin{tabular}{|ccccccc|}
\hline $\begin{array}{c}\text { Total } \\
\text { de casos }\end{array}$ & Santiago & Maipú & \multicolumn{4}{c|}{$\begin{array}{c}\text { Estación Cerrillos } \\
\text { Central }\end{array}$} \\
380 & 263 & 24 & 85 & 6 & 2 \\
\hline
\end{tabular}

Las cifras de la tabla representan el número de pacientes. PAC $=$ comuna Pedro Aguirre Cerda.
Estación Central concentra el 22\% de TBC de extranjeros y chilenos, y Cerrillos el 6,2\% de ambos grupos. En Maipú y comuna Pedro Aguirre Cerda (PAC) los casos extranjeros son escasos $(2 \%)$ (Tablas 7 y 8; Figura 3).

\section{Evolución temporal de los casos extranjeros}

La proporción de casos correspondientes a pacientes inmigrantes ha ido creciendo progresivamente a través del tiempo. Este grupo representaba cerca del 10\% de los casos de TBC el año 2005 y ha alcanzado una proporción cercana al 30\% el año 2014 (Tabla 9). La comuna de San-

Tabla 8. Chilenos con $\mathrm{TBC}$ según comunas. Programa de Control de la TBC, SSMC 2005 a 2014

\begin{tabular}{|cccccc|}
\hline $\begin{array}{c}\text { Total } \\
\text { de casos }\end{array}$ & Santiago & Maipú & \multicolumn{3}{c|}{$\begin{array}{c}\text { Estación Cerrillos } \\
\text { Central }\end{array}$} \\
\hline 1.453 & 596 & 414 & 317 & 90 & 36 \\
\hline
\end{tabular}

Las cifras de la tabla representan el número de pacientes. PAC $=$ comuna Pedro Aguirre Cerda.
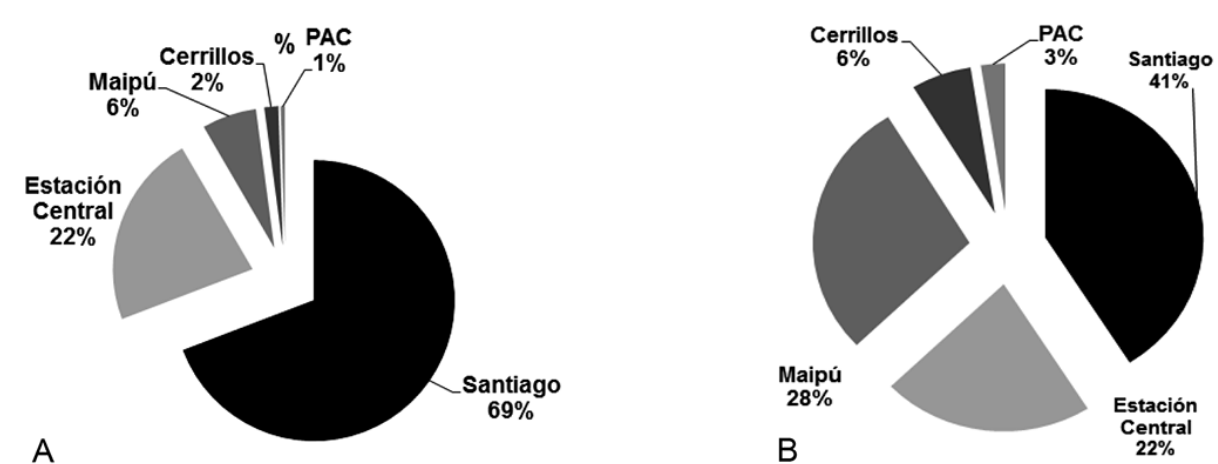

Figura 3. TBC en extranjeros (A) y chilenos (B) según comunas. Programa de Control de la TBC, SSMC 2005 a 2014. PAC $=$ Comuna Pedro Aguirre Cerda.

Tabla 9. Casos anuales de TBC en chilenos y extranjeros. Programa de Control de la TBC, SSMC 2005 a 2014

\begin{tabular}{|ccccccc|}
\hline Año & Total & $\begin{array}{c}\text { Casos totales TBC } \\
\text { Chilenos }\end{array}$ & Extranjeros & Total & $\begin{array}{c}\text { Casos TBC PB } \\
\text { Chilenos }\end{array}$ & Extranjeros \\
\hline 2005 & 193 & 172 & 21 & 141 & 127 & 14 \\
\hline 2006 & 186 & 164 & 22 & 129 & 113 & 16 \\
\hline 2007 & 189 & 155 & 34 & 118 & 94 & 24 \\
\hline 2008 & 226 & 176 & 50 & 138 & 107 & 31 \\
\hline 2009 & 194 & 151 & 43 & 137 & 108 & 29 \\
\hline 2010 & 169 & 129 & 40 & 117 & 89 & 28 \\
\hline 2011 & 216 & 172 & 44 & 94 & 87 & 7 \\
\hline 2012 & 107 & 89 & 18 & 72 & 60 & 12 \\
\hline 2013 & 158 & 108 & 50 & 100 & 65 & 35 \\
\hline 2014 & 195 & 137 & 58 & 121 & 86 & 35 \\
\hline
\end{tabular}

Las cifras de la tabla representan el número de pacientes. $\mathrm{PB}=$ pulmonar bacteriológicamente demostrada. 
tiago es la que concentra más casos de TBC en inmigrantes. La proporción de casos correspondientes a extranjeros en esta comuna se incrementó extraordinariamente desde $17 \%$ el año 2005 hasta $49 \%$ el año 2014. Pero, lo más llamativo es el importante aumento de la proporción de extranjeros en los casos de TBC bacilífera, que creció desde 17,6\% el año 2005 hasta representar el 55,6\% de los casos de esta categoría en dicha comuna el año 2014 (Tabla 10 y Figuras 4 a 7).

Tabla 10. Casos anuales de TBC en chilenos y extranjeros en la comuna de Santiago. Programa de Control de la TBC, SSMC 2005 a 2014

\begin{tabular}{|ccccccc|}
\hline Año & Total & $\begin{array}{c}\text { Casos totales TBC } \\
\text { Chilenos }\end{array}$ & Extranjeros & Total & \multicolumn{2}{c|}{$\begin{array}{c}\text { Casos TBC PB } \\
\text { Chilenos }\end{array}$} \\
\hline 2005 & 70 & 58 & 12 & 51 & 42 & Extranjeros \\
2006 & 63 & 55 & 8 & 40 & 35 & 5 \\
2007 & 87 & 59 & 28 & 54 & 34 & 20 \\
2008 & 115 & 75 & 40 & 73 & 48 & 25 \\
\hline 2009 & 107 & 75 & 32 & 77 & 55 & 22 \\
2010 & 91 & 59 & 32 & 67 & 43 & 24 \\
2011 & 111 & 83 & 28 & 44 & 41 & 3 \\
2012 & 56 & 41 & 14 & 38 & 28 & 10 \\
\hline 2013 & 97 & 59 & 38 & 63 & 37 & 26 \\
\hline 2014 & 63 & 32 & 31 & 36 & 16 & 20 \\
\hline
\end{tabular}

Las cifras de la tabla representan el número de pacientes. $\mathrm{PB}=$ pulmonar bacteriológicamente demostrada.

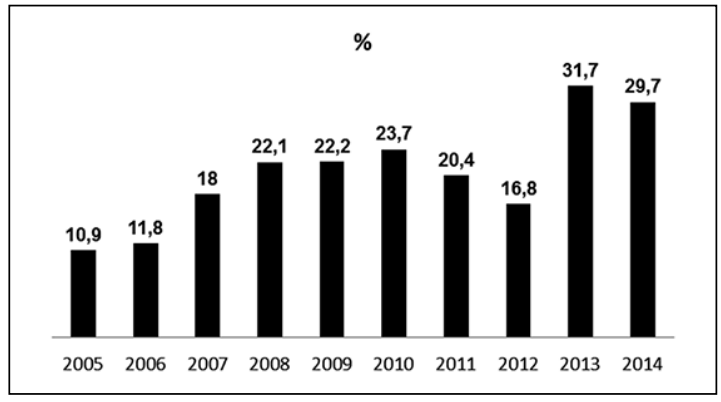

Figura 4. Proporción anual (\%) de casos de TBC correspondiente a extranjeros. Programa de Control de la TBC, SSMC.

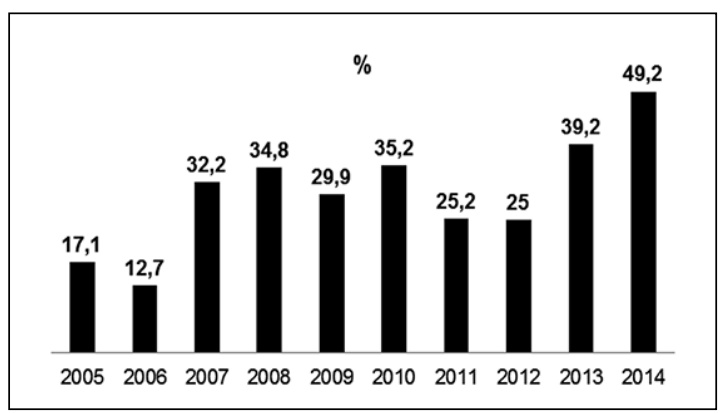

Figura 6. Frecuencia anual (\%) de TBC correspondiente a extranjeros en la comuna de Santiago. SSMC. Programa de Control de la TBC.

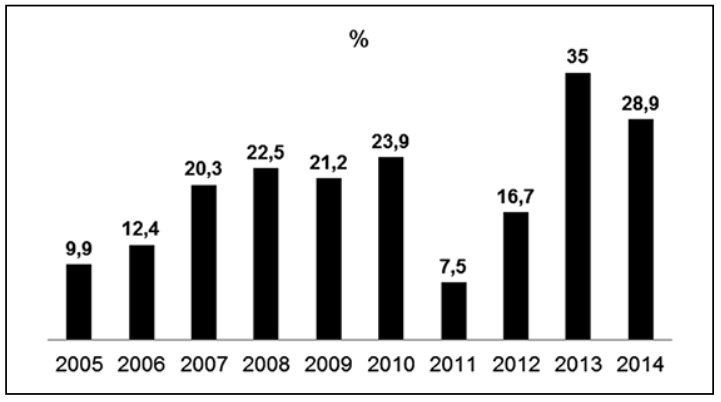

Figura 5. Proporción anual (\%) de casos de TBC pulmonar bacteriológicamente demostrada correspondiente a extranjeros. Programa de Control de la TBC, SSMC.

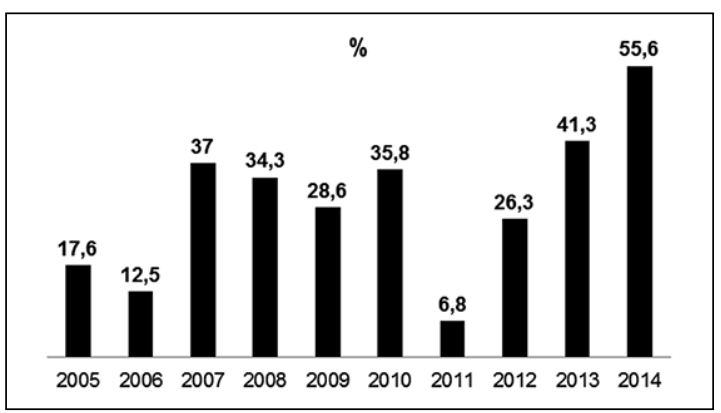

Figura 7. Frecuencia anual (\%) de TBC pulmonar bacteriológicamente demostrada, correspondiente a extranjeros de la comuna de Santiago, SSMC. Programa de Control de la TBC. 
Tabla 11. Resultados terapia anti-TBC en chilenos y extranjeros. Programa de Control de la TBC, SSMC 2005 a 2014

\begin{tabular}{|lccccccccc|}
\hline & $\begin{array}{c}\text { n de casos } \\
\text { evaluados }\end{array}$ & \multicolumn{2}{c}{ Éxito } & n & \% & Pérdida de seguimiento & \multicolumn{2}{c|}{ Muertes } & \multicolumn{2}{c|}{ Fracaso } \\
Chilenos & 686 & 559 & 81,5 & 53 & 7,7 & 75 & 10,6 & 1 & 0,2 \\
Extranjeros & 137 & 120 & 87,6 & 15 & 11 & 2 & 1,5 & 0 & 0 \\
Total & 823 & 879 & 82,5 & 68 & 8,3 & 75 & 9,1 & 1 & 0,1 \\
\hline
\end{tabular}

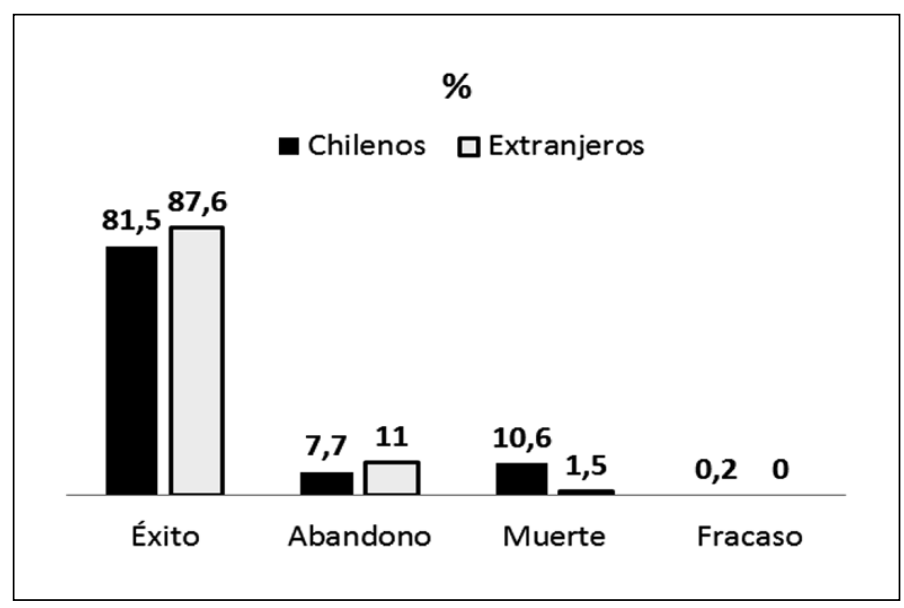

Figura 8. Eficacia terapia anti-TBC en chilenos y extranjeros. Programa de Control de la TBC, SSMC 2005 a 2014. Cada columna representa el \% de éxito, abandono, muertes y fracaso del tratamiento respectivamente.

\section{Eficacia del tratamiento en extranjeros}

Se pudo evaluar los resultados del tratamiento de la tuberculosis en los registros de 1.004 casos, excluyendo los traslados, muchos de los cuales continuaron su terapia en sus lugares de destino. La proporción de traslados fue alta $(18 \%)$, siendo mayor en el grupo de extranjeros $(22,6 \%)$ que en los chilenos $(17 \%)$. Se pudo conocer los resultados del tratamiento en el seguimiento de 823 pacientes, 686 chilenos $(83,4 \%)$ y 137 extranjeros $(16,6 \%)$. El éxito global alcanzó a $82,5 \%$ y fue mejor en inmigrantes $(87,6 \%)$ que en chilenos $(81,5 \%)$. La mortalidad fue significativamente mayor en el grupo de chilenos $(10,6 \%$ versus $1,5 \%$ en extranjeros). La proporción de abandonos fue elevada $(8,3 \%)$ y fue mayor en el grupo de extranjeros $(11 \%)$ que en chilenos $(7,7 \%)$. Los fracasos a la terapia son excepcionales en ambos grupos (Tabla 11 y Figura 8).

\section{Discusión}

Se pudo determinar que los inmigrantes son un grupo importante dentro de la casuística de TBC del Servicio de Salud Metropolitano Central. Esto es más relevante para la comuna de Santiago don- de la mitad de sus casos pulmonares bacteriológicos corresponden a extranjeros. Es por lo tanto necesario intensificar las actividades de detección de casos en sintomáticos respiratorios dentro de la población de inmigrantes de esta comuna. Para ampliar esta actividad se debe agregar una pesquisa activa fuera de los establecimientos de salud, para lo cual se hace necesario establecer alianzas con la comunidad buscando la cooperación de organizaciones que apoyan a las familias de extranjeros y disponer de tecnologías de biología molecular de mayor rendimiento diagnóstico que la bacteriología convencional ${ }^{10,11}$. La fácil integración de las culturas chilena-inmigrante debido a similitudes socio-culturales con influencia hispánica, ha sido un elemento de apoyo para lograr la adherencia de los extranjeros a nuestro sistema de salud. Sin embargo, aún existen barreras de acceso que van desde las dificultades en la identificación de las personas, hasta la falta de previsión en salud de los extranjeros. No obstante lo anterior, una gran fortaleza del Programa de Control de la Tuberculosis de Chile radica en que sus acciones de diagnóstico y tratamiento son gratuitas e independientes del tipo de previsión de salud, tanto para chilenos como para extranjeros ${ }^{5}$.

Respecto a los resultados de la terapia, ob- 
servamos que la eficacia del tratamiento de la tuberculosis no es óptima, tanto en extranjeros como chilenos. La OMS establece, incluso para regiones con bajo control en la administración de los medicamentos, lograr una curación de por lo menos el $85 \%$ de los $\operatorname{casos}^{12,13}$. Nuestro país es aún más exigente y propone una meta de éxito para la curación de $90 \%$. Para lograrlo se deberá cautelar con más precisión el destino de los traslados de pacientes en ambos grupos, ya que esta imprecisión del seguimiento afecta en forma importante el grado de éxito de la terapia. La letalidad elevada en el grupo de chilenos ha sido analizada a través de auditorías de mortalidad y se ha logrado establecer que cerca de la mitad de las muertes obedece a causas distintas a la TBC; aunque también es cierto, que en los casos de fallecidos por causa directamente relacionada a la enfermedad hay una fuerte asociación con diagnóstico tardío (muertes muy cercanas al momento del diagnóstico; TBC muy avanzadas, pacientes en situación de calle o con patologías asociadas (VIH, enfermedades crónicas, etc. $)^{14}$. La baja proporción de fracasos del tratamiento se relaciona con la baja frecuencia de resistencia a los fármacos utilizados en el tratamiento de la tuberculosis ${ }^{15}$, en nuestro país, en gran parte debido a la alta cobertura de una terapia supervisada por personal capacitado (DOTS) ${ }^{16}$ y por el control central en la distribución de los fármacos utilizados para el tratamiento de esta enfermedad, que sólo están disponibles en el sector público de salud.

Finalmente, debemos insistir en la necesidad de aumentar la colaboración de los diferentes niveles de la red asistencial de salud en la pesquisa activa de sintomáticos respiratorios en inmigrantes, sin estigmatizar a esta población ${ }^{17}$, sino como la intensificación de las acciones del Programa de Control de la Tuberculosis, especialmente en los contactos de casos pulmonares bacilíferos de este grupo de población, donde es más costoefectivo ${ }^{18}$.

\section{Conclusiones}

Los inmigrantes han incidido en la situación epidemiológica actual de la tuberculosis en el Servicio de Salud Metropolitano Central, ya que su aporte a la casuística de la enfermedad ha seguido una tendencia de aumento progresivo, llegando actualmente a contribuir con el 30\% de los casos notificados de tuberculosis. Para la comuna de Santiago este impacto es aún mayor, llegando a representar la mitad de los casos de tuberculosis de esta comuna. El aporte de los inmigrantes no se limita a casos pulmonares bacteriológicamente demostrados; también desarrollan formas extra-pulmonares en la misma proporción que los pacientes chilenos. La eficacia del tratamiento en extranjeros aún no es óptima, pero es mejor que la mostrada en los pacientes chilenos y se ve afectada por la alta proporción de abandonos, a diferencia de los chilenos en los que la letalidad es mayor. El Programa de Control de la Tuberculosis de este Servicio de Salud debe incorporar estrategias tendientes a asegurar y mejorar el diagnóstico oportuno de la TBC en chilenos y en extranjeros y a desarrollar estrategias para mejorar la adherencia al tratamiento.

\section{Bibliografía}

1.- TB. A global emergency. WHO report on the tuberculosis epidemic, 1994. WHO/TB/94.177.

2.- OPS. La OMS se marca el objetivo de eliminar la tuberculosis en más de 30 países. 2014 [citado el 29 de noviembre de 2014]. En: http://www.paho.org/hq/index. php?option $=$ com_content $\&$ view $=$ article \&id $=9751 \&$ Ite mid=1 26\&lang=es.

3.- OMS. Nota descriptiva de prensa $\mathrm{N}^{\circ} 104$ de octubre 2015.mediainquiries@who.int.

4.- Programa de OMS contra la tuberculosis. Marco para el control eficaz de la tuberculosis. WHO/TB/94.179(s).

5.- Programa Nacional de Control y eliminación de la tuberculosis. Normas técnicas para el control y la eliminación de la tuberculosis. 2014. En: http://web.minsal.cl/ sites/default/files/NorMa_teCNICa_tuberCuloSIS.pdf.

6.- PEÑA C, FARGA V. El difícil camino del control sanitario de la tuberculosis. Rev Chil Enferm Respir 2012; 28: 311-8.

7.- Programa Nacional de Control y eliminación de la tuberculosis. Informe situación 2014. MINSAL de Chile.

8.- YÁÑEZ A. Tuberculosis en inmigrantes. Situación Chile-Perú. Rev Chil Enferm Respir 2010; 26: 164-5.

9.- Programa Nacional de Control y eliminación de la tuberculosis. Informe situación Servicio de Salud Metropolitano Central 2014.

10.- NISHIKIORI N, VAN WEEZENBEEK C. Target prioritization and strategy selection for active case-finding of pulmonary tuberculosis: a tool to support country-level project planning. BMC Public Health 2013; 13: 97. Published online 2013 Feb 2. doi: 10.1186/1471-245813-97.

11.- Availability of an Assay for Detecting Mycobacterium tuberculosis, Including Rifampin-Resistant Strains, and Considerations for Its Use-United States, 2013. MMWR 2013; 62 (41): 821-4.

12.- WORLD HEALTH ORGANIZATION. Guidelines for the Control of Tuberculosis. Through DOTS Strategy 
in Pacific Island Countries. www.wpro.who.int/publications/docs/tbguide.pdf

13.- Guidelines for treatment of tuberculosis. Fourth edition WHO. 2010.

14.- Auditoría de muertes por tuberculosis. Programa de control de la tuberculosis del Servicio de Salud Metropolitano Central. 2015.

15.- Informe Instituto de Salud Pública de Chile. Evaluación situación nacional de tuberculosis de Chile. 2014.

16.- The five elements of DOTS. Element 3. Standardized treatment, with supervision and patient support. Dispo- nible en: www.who.int/tb/dots/whatisdots.

17.- ABARCA T B, PELL C, BUENO CAVANILLAS A, GUILLÉN SOLVAS J, POOL R, ROURA M. Tuberculosis in migrant populations. A systematic review of the qualitative literature. PLoS One 2013; 8 (12): e82440. Published online 2013 Dec 5. doi: 10.1371/journal. pone.0082440.

18.- DASGUPTA K, MENZIES D. Cost-effectiveness of tuberculosis control strategies among immigrants and refugees Eur Respir J 2005; 25: 1107-16. doi: 10.1183/09031936.05.00074004.

Correspondencia a:

Dr. Carlos Peña Mantinetti

Programa de Control y Eliminación de la Tuberculosis, Servicio de Salud Metropolitano Central.

Santa Rosa 1234, Santiago,

Región Metropolitana, Chile.

Email: ruth.caamaño@redsalud.gov.cl 